\title{
Piriform sinus fistula management approach - our experience
}

\author{
Dan Cristian Gheorghe ${ }^{1,5}$, Adina Zamfir-Chiru-Anton², LE Ene ${ }^{3}$, AE Stanciu 4,5 \\ ${ }^{1}$ ENT Department, "MS Curie" Hospital, Bucharest, Romania \\ 2ENT Department, "Gr. Alexandrescu" Hospital, Bucharest, Romania \\ ${ }^{3}$ ENT Department, City Hospital, Slatina, Romania \\ ${ }^{4}$ Department of Carcinogenesis and Molecular Biology, Institute of Oncology, Bucharest, Romania \\ 5"Carol Davila" University of Medicine and Pharmacy, Bucharest, Romania
}

\begin{abstract}
Branchial anomalies are a group of malformations resulting from incomplete closure of the pharyngeal pouches and clefts. They manifest as cysts, fistulae and sinus tracts located in the neck. We present the case of a 3 years-old girl admitted to the Surgery Department of our hospital for reccurent abssceses on the left side of her neck, lateral to the sternocleidomastoid muscle. Management approach should be tailored according to the dimensions of the sinus and its relationships with the carotid artery and reccurent laryngeal nerve.
\end{abstract}

Keywords: branchial anomalies, fistula, piriform sinus, child

\section{INTRODUCTION}

Branchial anomalies are a group of malformations resulting from incomplete closure of the pharyngeal pouches and clefts. They manifest as cysts, fistulae and sinus tracts located in the neck. According to the anatomical structures involved, second branchial clefts are the most common.

Third branchial clefts remnants are rare. Their incidence is cited as $3-10 \%$ of all branchial anomalies [1]. They usually manifest as piriform sinus tracts. Diagnosis can be made by thorough endoscopic examination of the hypopharynx. Imagistics by CT, ultrasonography or MRI can delineate the lesion and aid in planning surgery. Barium esophagram can also demonstrate the presence of a fistula, but results can be inconstant [2].

Fourth branchial cleft remnants are very similar to third pouch anomalies described, making inclusion of both entities into the piriform sinus fistulas term more appropriate. Still, anatomical position of the latter, with regard to superior and reccurent laryngeal nerves, can make a difference. Also, the direction of the sinus is more commonly downwards, toward the thyroid gland [3].

The lining of piriform sinus tracts are usually made of columnar ciliated epithelium.

Management approach is by complete surgical removal. Incomplete resection can be followed by local infectious recurrence. Fiberoptic endoscopy can help identify the sinus tract [4].

\section{CASE PRESENTATION}

A 3 years-old girl presented to the Surgery Department of our hospital for reccurent abssceses on the left side of her neck, lateral to the sternocleidomastoid muscle. Previous drainage of the cervical spaces have led to temporary relief but a more detailed diagnosis was performed.

Rigid endoscopy with general anesthesia noted a small fistula opening on the left side of the apex of the piriform sinus. Catetherisation of the sinus was difficult to maintain during atempted concomitant excision performed by the surgeon. Endo- 
scopic cautherisation was also used as an adjunct to management approach.

Reccurence occurred 1 month later and prompted for MRI imaging of the pharyngo-laryngeal region (see figures 1-2). The fistula could be elicited emerging from the left piriform sinus and descending towards the thyroid gland region and having close relationship ( $2 \mathrm{~mm})$ with the common carotid artery. A total length of $3,5 \mathrm{~cm}$ of the sinus was recorded.

We recommended neck dissection type surgery in order to avoid reccurent laryngeal nerve paralysis or significant bleeding accident during surgery. The patient was taken in charge by the pediatric surgical department.

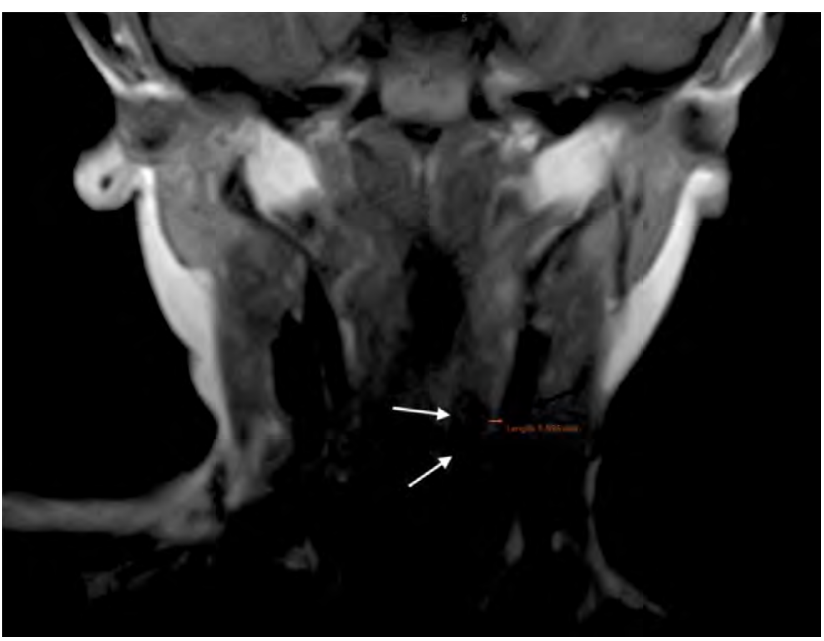

FIGURE 1. MRI of the case - small $12 / 7 \mathrm{~mm}$ cavity located to the left side of trachea (white arrows), at close proximity with common carotid artery (black arrow)

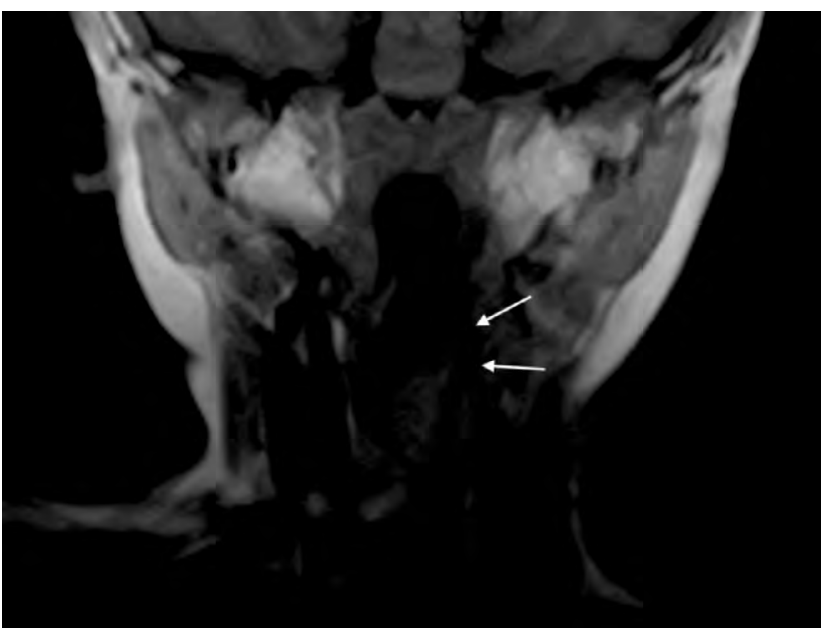

FIGURE 2. MRI of the case - visible sinus opening in the piriform fossa (arrows)

\section{DISCUSSION}

Third or fourth brachial cleft fistulas can be identified at endoscopic examination as piriform sinus fistulas. Theoretically, the course of such anomalies is passing behind the internal carotid artery before entering the lateral wall of the piriform sinus. Location is mostly on the left side [2]. Retropharyngeal abscess has been reported associated with this anomaly [5].

Forth branchial cleft fistulas have a course downwards to the thyroid gland. Abscesses of the latter are common $[6,7]$.

Clinical symptoms tend to relapse after simple antibiotic regimen and/or surgical drainage. Clinical presentation should direct investigations towards branchial malformations, with associated fistulas or cysts. Rarely, abcesses originating from branchial malformations can produce airway compression and compromise [8].

Best diagnosis of piriform sinus fistulas is obtained by CT scanning [2]. Fiberoptic endoscopic view of the pharyngeal opening is not always obvious [9]. Ultrasound can reveal ill-defined, heterogeneous, hypoechoic mass in the neck but is not conclusive [10].

Complete surgical excision of the tract is necessary to prevent infectious recurrences. Thyroid cartilage incision is useful for better exposure of the sinus tract $[8,11,12]$. Closure of the hypopharyngeal orifice can be acomplished by electrocauthery [13] or purse suture during surgical excision. Endoscopic cautherisation is described and seem less invasive than open cervical surgery in most of the cases but more procedures can be needed for definitive success [14].

Some authors used neck dissection for proper identification of the fistula and preserving important tissues $[15,16]$. There is also a report of endoscopic excision of a short length piriform sinus fistula with suture closure in the end of the procedure [17].

Recurrences are more frequently seen after previous infections of the fistula [18] and incision or drainage before definitive surgical excision [19]. Need for repeat surgery is common [1].

Complications can occur with surgery for branchial cleft fistulas. Recurrent laryngeal nerve paralysis was comunicated [20].

Our patient provided the same surgical difficulties related in other reports. Multiple interventions made complete excision a challenge even for the experienced surgeon. Teamwork is essential in order to correctly assess a branchial fistula originating from the piriform sinus. Preventing complications as well as reccurences need proper assistance and all possible management approaches for clinical success. Due to clear downward direction of the 
fistula in our patient we appreciate it as a fourth pouch branchial anomaly.

In our experience, electrocautherisation was not able to prevent cervical recurrent infections and surgery should address complete excision of the sinus.

\section{CONCLUSIONS}

Third and forth branchial pouch remnants can manifest similar as piriform fossa fistulas. Their di-

\section{REFERENCES}

1. Choi SS, Zalzal GH. Branchial anomalies: A review of 52 cases. Laryngoscope, 1995;105(9 Pt 1):909-13.

2. Park SW et al. Neck infection associated with pyriform sinus fistula: Imaging findings. AJNR Am J Neuroradiol. 2000;21(5):817-22.

3. Waldhausen JH. Branchial cleft and arch anomalies in children. Semin Pediatr Surg. 2006;15(2):64-9.

4. Godin MS et al. Fourth branchial pouch sinus: Principles of diagnosis and management. Laryngoscope, 1990;100(2 Pt 1):174-8.

5. Huang RY et al. Third branchial cleft anomaly presenting as a retropharyngeal abscess. Int J Pediatr Otorhinolaryngol. 2000; 54(2-3):167-72.

6. Takai SI et al. Internal fistula as a route of infection in acute suppurative thyroiditis. Lancet, 1979;1(8119):751-2.

7. Narcy $P$ et al. Fistulae of the fourth endobranchial pouch. Int J Pediatr Otorhinolaryngol. 1988;16(2):157-65.

8. Liberman $\mathrm{M}$ et al. Ten years of experience with third and fourth branchial remnants. J Pediatr Surg. 2002;37(5):685-90.

9. Li W et al. Branchial anomalies in children: A report of 105 surgical cases. Int J Pediatr Otorhinolaryngol. 2018;104:14-18.

10. Liu Z, Tang SS. Diagnosis of pyriform sinus fistula in children via ultrasonography. Am J Otolaryngol. 2013;34(5):579-81.

11. Pereira KD et al. Management of anomalies of the third and fourth branchial pouches. Int J Pediatr Otorhinolaryngol. 2004;68(1):43-50.

12. Nonomura $\mathrm{N}$ et al. Surgical approach to pyriform sinus fistula. $A m \mathrm{~J}$ Otolaryngol. 1993;14(2):111-5. agnosis should rely on imagistics combined with rigid endoscopic examination of the hypopharynx. Management approach should be tailored according to the dimensions of the sinus and its relationships with the carotid artery and reccurent laryngeal nerve. Experienced surgeon is definitely needed for long term success.

Conflict of interest: none declared Financial support: none declared

13. Jordan JA et al. Endoscopic cauterization for treatment of fourth branchial cleft sinuses. Arch Otolaryngol Head Neck Surg. 1998; 124(9):1021-4.

14. Derks, L.S et al. Surgery versus endoscopic cauterization in patients with third or fourth branchial pouch sinuses: A systematic review. Laryngoscope, 2016. 126(1):212-7.

15. Cai $Q$ et al. Resection of recurrent branchial cleft deformity using selective neck dissection technique. Int J Pediatr Otorhinolaryngol. 2014;78(7):1071-3.

16. Blackwell KE, Calcaterra TC. Functional neck dissection for treatment of recurrent branchial remnants. Arch Otolaryngol Head Neck Surg. 1994;120(4):417-21.

17. Kamide $D$ et al. Minimally invasive surgery for pyriform sinus fistula by transoral videolaryngoscopic surgery. Am J Otolaryngol. 2015; 36(4):601-5.

18. Schroeder JW Jr., Mohyuddin M, Maddalozzo J. Branchial anomalies in the pediatric population. Otolaryngol Head Neck Surg. 2007; 137(2):289-95.

19. Vermeire VM, Daele JJ. Second branchial cleft-pouch set fistulae, sinuses and cysts in children. Acta Otorhinolaryngol Belg. 1991; 45(4):437-42.

20. Nicollas $R$ et al. Fourth branchial pouch anomalies: A study of six cases and review of the literature. Int $J$ Pediatr Otorhinolaryngol. 1998; 44(1):5-10. 